\title{
Analiza portfela rynkowego
}

\section{Wstęp}

Inwestowanie $w$ akcje jest czynnością bardzo złożoną gdyż akcje przynoszące duży zysk są na ogół obarczone również dużym ryzykiem. Okazuje się, że inwestowanie w kilka rodzajów akcji pozwala na uzyskanie zadowalającego zysku przy możliwym do zaakceptowania ryzyku. Taką koncepcję inwestycyjną nazywa się tworzeniem portfela, a zróżnicowanie akcji w tym portfelu jego dywersyfikacją. Ustalenie składu portfela o minimalnym ryzyku czyni się zazwyczaj metodami analizy matematycznej, choć dla portfeli dwuskładnikowych można to osiagać również metodami geometrii analitycznej [6].

Istnieje jednak inny sposób zmniejszania ryzyka portfela. Tym sposobem jest uwzględnienie w nim tzw. instrumentów finansowych wolnych od ryzyka, z których najbardziej popularnymi są obligacje. Negatywną stroną instrumentów wolnych od ryzyka jest fakt, iż charakteryzują się one niższą oczekiwaną stopą zwrotu niż akcje, a zatem dają mniejszy zysk.

\section{Portfel rynkowy}

Włączenie instrumentów wolnych od ryzyka do portfela traktuje się jako utworzenie portfela dwuskładnikowego, w którym pierwszy składnik stanowią instrumenty wolne od ryzyka, a drugi - portfel zawierający ryzykowne akcje.

Rozważmy portfel $\mathrm{P}$ złożony $\mathrm{z}$ dwóch rodzajów akcji $\mathrm{A}$ i B przynoszących zysk (wyrażony przez oczekiwaną stope zwrotu) $z_{A}$ i $z_{B}$, oraz obarczonych ryzykiem (wyrażonym przez odchylenie standardowe) $\mathrm{s}_{\mathrm{A}}$ i $\mathrm{s}_{\mathrm{B}}$ i powiązanych według współczynnika korelacji $\rho_{A B} \in(-1,1)$. Geometryczną zależność zysku od ryzyka wyraża następujące równanie hiperboli [6]:

$$
\frac{s^{2}}{a^{2}}-\frac{\left(z-z_{0}\right)^{2}}{b^{2}}=1
$$

gdzie: 


$$
\begin{aligned}
& a^{2}=\frac{s_{A}^{2} \cdot s_{B}^{2} \cdot\left(1-\rho_{A B}^{2}\right)}{s_{A}^{2}-2 \cdot s_{A} \cdot s_{B} \cdot \rho_{A B}+s_{B}^{2}} \\
& b^{2}=\frac{s_{A}^{2} \cdot s_{B}^{2} \cdot\left(z_{B}-z_{A}\right)^{2} \cdot\left(1-\rho_{A B}{ }^{2}\right)}{\left(s_{A}^{2}-2 \cdot s_{A} \cdot s_{B} \cdot \rho_{A B}+s_{B}\right)^{2}} \\
& z_{0}=\frac{z_{B} \cdot s_{A}^{2}-\left(z_{A}+z_{B}\right) \cdot s_{A} \cdot s_{B} \cdot \rho_{A B}+z_{A} \cdot s_{B}{ }^{2}}{s_{A}^{2}-2 \cdot s_{A} \cdot s_{B} \cdot \rho_{A B}+s_{B}^{2}}
\end{aligned}
$$

Niech D oznacza obligację przynoszącą zysk zp. Praktyka pokazuje, że akcje przynoszą na ogół większy zysk niż obligacje. Gdyby bowiem było $z_{D}>z_{A}$ lub $z_{D}>z_{B}$, to nie tworzylibyśmy portfela złożonego $\mathrm{z}$ ryzykownych akcji, lecz kupilibyśmy obligacje mające zerowe ryzyko. Bez zmniejszania ogólności rozważań możemy więc przyjąć, że $\mathrm{z}_{\mathrm{D}}<\mathrm{z}_{\mathrm{A}}$ oraz $\mathrm{z}_{\mathrm{D}}<\mathrm{z}_{\mathrm{B}}$.

Bez zmniejszania ogólności rozważań możemy przyjąć też, że $\mathrm{z}_{\mathrm{A}}<\mathrm{z}_{\mathrm{B}}$ oraz $\mathrm{s}_{\mathrm{A}}<\mathrm{s}_{\mathrm{B}}$. Gdyby bowiem było $\mathrm{np} . \mathrm{z}_{\mathrm{A}}>\mathrm{z}_{\mathrm{B}}$ i $\mathrm{s}_{\mathrm{A}}<\mathrm{s}_{\mathrm{B}}$, to nie tworzylibyśmy portfela złożonego $\mathrm{z}$ tych akcji, lecz kupilibyśmy wyłącznie akcje A. Ilustracją powyższej sytuacji jest rysunek 1 .

\section{Rysunek 1}

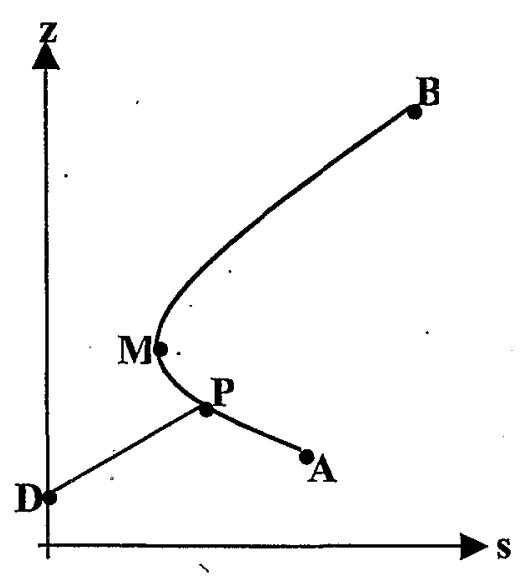

Portfel złożony z obligacji i dwóch rodzajów akcji

Odcinek DP ilustruje wszystkie portfele trójskładnikowe złożone z akcji A, $\mathrm{B}$ i obligacji $\mathrm{D}$, przy czym skrajny punkt $\mathrm{D}$ obrazuje portfel złożony wyłącznie z obligacji, zaś punkt P - wyłącznie z akcji. Przesuwając się po odcinku DP w kierunku od D do P zwiększamy w takim portfelu udział akcji kosztem obli- 
gacji. $Z$ kolei, przesuwając się po hiperboli z punktem $P$ w kierunku $B$ osiagamy minimalne ryzyko portfela złożonego $\mathrm{z}$ samych akcji w punkcie $\mathrm{M}$, a maksymalny zysk w punkcie C, w którym odcinek DP jest styczny do tej hiperboli. Ten „najlepszy” portfel nazywa się portfelem rynkowym (ang. market portfolio) [3].

\section{Rysunek 2}

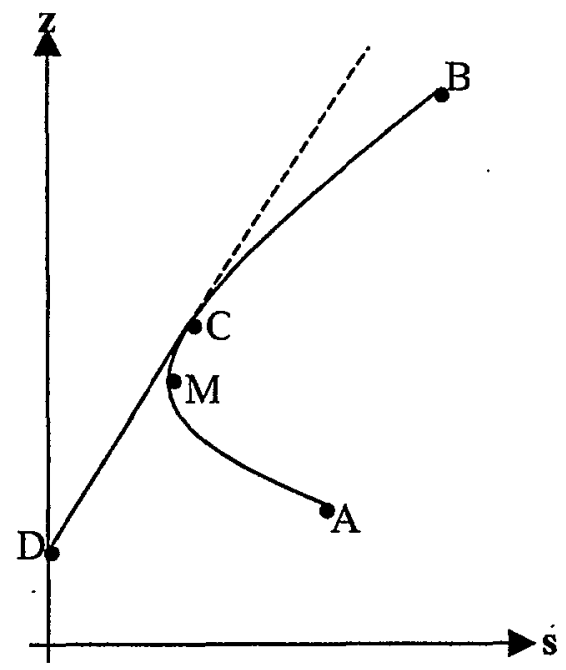

Portfel rynkowy

Przyjmijmy że punkty zaznaczone na wykresie mają współrzędne:
$\mathrm{A}=\left(\mathrm{s}_{\mathrm{A}}, \mathrm{z}_{\mathrm{A}}\right)$
$\mathrm{B}=\left(\mathrm{s}_{\mathrm{B}}, \mathrm{z}_{\mathrm{B}}\right)$
$\mathrm{C}=\left(\mathrm{s}_{\mathrm{C}}, \mathrm{z}_{\mathrm{C}}\right)$
$\mathrm{D}=\left(\mathrm{s}_{\mathrm{D}}, \mathrm{z}_{\mathrm{D}}\right)=\left(0, \mathrm{z}_{\mathrm{D}}\right)$

Prosta przechodząca przeż punkty $\mathrm{C}$ i D ma następujące równanie:

$$
z-z_{D}=\frac{z_{C}-z_{D}}{s_{C}-s_{D}} \cdot\left(s-s_{D}\right)
$$

Stąd

$$
z=z_{D}+\frac{z_{C}-z_{D}}{s_{C}} \cdot s
$$

Prosta określona tym wzorem nazywana jest linią rynku kapitałowego (ang. capital market line), w skrócie CML.

Dla każdego portfela $\mathrm{z}$ odcinka DC z nieujemnymi udziałami akcji A i B oraz obligacji D mamy: 
$\mathrm{s} \in\left[0, \mathrm{~s}_{\mathrm{C}}\right]$ oraz $\mathrm{z} \in\left[\mathrm{z}_{\mathrm{D}}, \mathrm{z}_{\mathrm{C}}\right]$

$\mathrm{Z}$ równania (5) linii rynku kapitałowego wynika, że zysk każdego portfela $\mathrm{z}$ tej linii jest sumą dwóch składników. Pierwszy składnik stanowi zysk $z_{\mathrm{D}}$ obligacji. Jest on rozumiany jako „cena czasu”. Oznacza to, że każda inwestycja jest rezygnacją $z$ bieżącej konsumpcji na rzecz przyszłych korzyści, a zatem również poświęceniem czasu. Zapłatą dla inwestującego za to wyrzeczenie jest co najmniej zysk obligacji. Drugi składnik jest interpretowany jako „cena ryzyka". Inwestowanie w akcje oznacza, oprócz odroczenia bieżącej konsumpcji, również ponoszenie ryzyka. Przyszłość jest niepewna, więc przyszłe korzyści mogą wystąpić, ale nie muszą. W zamian za ryzyko związane $z$ niepewnym zyskiem inwestorzy oczekują wyższej zapłaty, niż jedynie zysk obligacji.

Nadwyżka ta jest iloczynem $\frac{z_{C}-z_{D}}{s_{C}} \cdot s$, przy czym:

wyrażenie $\frac{z_{C}-z_{D}}{s_{C}}$ jest premią za ryzyko, czyli dodatkowym procentem dochodu, jaki można przeciętnie uzyskać na rynku za zwiększenie ryzyka o jednostkę, a zatem jest ceną jednostki ryzyka, s jest ryzykiem portfela.

$\mathrm{Z}$ powyższych rozważań wynika, że interpretacja linii rynku kapitałowego może być następująca:

Zysk portfela $=$ cena czasu $+($ cena jednostki ryzyka $\cdot$ ryzyko portfela $)$ lowego.

Na podstawie rysunku 2 przeprowadzimy teraz analizę linii rynku kapita-

Wybór konkretnego portfela z linii kapitałowej jest uzależniony od skłonności inwestora do ryzyka. Portfel D zawierający wyłącznie obligacje wybierze inwestor cechujący się największą awersją do ryzyka. Inwestor ten pożycza swój kapitał emitentowi obligacji w zamian za oprocentowanie w postaci zysku $z$ tej obligacji.

Udział akcji w portfelu zwiększa się, a udział obligacji maleje w miare wzrostu skłonności inwestora do ryzyka. Wówczas maleje także ilość pożyczonych emitentowi pieniędzy. Duża skłonność inwestora do ryzyka spowoduje, że dokona on wyboru portfela $\mathrm{C}, \mathrm{w}$ którym udział instrumentów wolnych od ryzyka jest zerowy, natomiast akcji - stuprocentowy.

Inwestorzy o jeszcze większej skłonności do ryzyka sprzedadzą obligacje z przeznaczeniem pozyskanych środków na zakup dodatkowych akcji. Zdecydują się oni na konstrukcję portfeli o jeszcze wyższej stopie zwrotu, ale jednocześnie wyższym ryzyku niż portfel rynkowy $\mathrm{C}$, czyli portfeli znajdujących się na linii kapitałowej po prawej stronie portfela $\mathrm{C}$. W takiej sytuacji zostanie 
zbudowany portfel dwuskładnikowy o udziałach $w_{D}<0$ oraz $1-w_{D}>1$. Jest to zagadnienie tzw. krótkiej sprzedaży w teorii portfela.

Równanie hiperboli i równanie linii rynku kapitałowego pozwalają wyznaczyć, jakie powinny być udziały akcji A i B oraz obligacji $D$, aby w efekcie powstał portfel przynoszący zysk $z$ przy określonym z góry ryzyku $s$ (lub równoważnie obarczony ryzykiem $s$ przy zadanym z góry zysku $z$ ).

Styczna DC do hiperboli (1) ma równanie:

$$
\mathrm{DC}: \frac{s_{C} \cdot s}{a^{2}}-\frac{\left(z_{C}-z_{0}\right) \cdot\left(z-z_{0}\right)}{b^{2}}=1
$$

Ponieważ $\mathrm{D} \in \mathrm{DC}$, więc

$$
0-\frac{\left(z_{C}-z_{0}\right) \cdot\left(z_{D}-z_{0}\right)}{b^{2}}=1
$$

Stąd

$$
z_{c}=z_{0}+\frac{b^{2}}{z_{0}-z_{D}}
$$

$\mathrm{Z}$ drugiej strony, ponieważ $\mathrm{C} \in \mathrm{AB}$, więc

$$
\frac{s_{C}^{2}}{a^{2}}-\frac{\left(z_{C}-z_{0}\right)^{2}}{b^{2}}=1,
$$

skąd

$$
s_{C}=a \cdot \sqrt{1+\frac{b^{2}}{\left(z_{0}-z_{D}\right)^{2}}}
$$

wzory (7) i (8) pozwalają obliczyć zysk i ryzyko portfela rynkowego, a także ustalić zakres ich zmian z odcinka DC linii rynku kapitałowego:

$$
s \in\left\langle 0, s_{C}\right\rangle \quad z \in\left\langle z_{D}, z_{C}\right\rangle
$$

Portfel odpowiadający dowolnemu punktowi odcinka DC osiaga zysk:

$$
z=w_{D} \cdot z_{D}+\left(1-w_{D}\right) \cdot z_{C}
$$

lub równoważnie

$$
z=w_{D} \cdot z_{D}+w_{A} \cdot z_{A}+w_{B} \cdot z_{B}
$$


gdzie $\quad w_{A}+w_{B}+w_{D}=1$

Jednocześnie ryzyko tego portfela wynosi:

$$
s=w_{D} \cdot s_{D}+\left(1-w_{D}\right) \cdot s_{C}
$$

czyli:

$$
s=\left(1-w_{D}\right) \cdot s_{C}
$$

Stąd

$$
w_{D}=1-\frac{s}{s_{c}}
$$

Jednocześnie

$$
\left\{\begin{array}{l}
z_{A} \cdot w_{A}+z_{B} \cdot w_{B}=z-w_{D} \cdot z_{D} \\
w_{A}+w_{B}=1-w_{D}
\end{array}\right.
$$

$\mathrm{Z}$ powyższego układu równań otrzymujemy wzory na skład dowolnego portfela z odcinka DC:

$$
\dot{w}_{A}=\frac{\left|\begin{array}{cc}
z-w_{D} \cdot z_{D} & z_{B} \\
1-w_{D} & 1
\end{array}\right|}{z_{A}-z_{B}}: \quad w_{B}=\frac{\left|\begin{array}{cc}
z_{A} & z-w_{D} \cdot z_{D} \\
1 & 1-w_{D}
\end{array}\right|}{z_{A}-z_{B}}
$$

\section{Przyklad 1.}

Wyemitowano dwa rodzaje akcji: A - przeznaczonych na rozwój agroturystyki oraz B - przeznaczonych na rọzwój infrastruktury.. Podać zysk, ryzyko i skład portfela rynkowego utworzonego w odniesieniu do akcji A i B obarczonych ryzykiem odpowiednio 5 i $8 \%$, przynoszących zysk - 6 i $14 \%$, powiazzanych według współczynnika korelacji równego 0,5 oraz do obligacji przynoszącej zysk $2 \%$.

$$
\begin{array}{ll}
\mathrm{s}_{\mathrm{A}}=5 \% & \mathrm{~s}_{\mathrm{B}}=8 \% \\
\mathrm{z}_{\mathrm{A}}=6 \% & \mathrm{z}_{\mathrm{B}}=1.4 \% \\
\rho_{\mathrm{AB}}=0,5 & \dot{\mathrm{z}}_{\mathrm{D}}=2 \%
\end{array}
$$

Korzystając $\mathrm{z}$ (1) otrzymujemy

$$
\frac{s^{2}}{(4,95)^{2}}-\frac{(z-6,80)^{2}}{(5,66)^{2}}=1
$$

czyli

$$
a^{2}=24,50 \quad b^{2}=31,99 \quad z_{0}=6,80
$$

Dalej z (7) mamy 


$$
z_{c}=6,80+\frac{31,99}{6,80-2}=13,46, \quad \text { czyli } \quad z_{C}=13,46 \% .
$$

Z kolei z (8) mamy

$$
s_{C}=\sqrt{24,50} \cdot \sqrt{1+\frac{31,99}{(6,80-2)^{2}}}=7,65, \text { czyli } \quad s_{C}=7,65 \% .
$$

Udziały $\mathrm{w}_{\mathrm{A}}$ i $\mathrm{w}_{\mathrm{B}}$ liczymy ze wzorów na udział w portfelu dwuskładnikowym [6]:

$$
w_{A}=\frac{z_{B}-z}{z_{B}-z_{A}} \quad w_{B}=\frac{z-z_{A}}{z_{B}-z_{A}}
$$

$$
\text { np. } w_{A}=\frac{14-13,46}{14-6}=0,07 \quad w_{B}=1-w_{A}=0,93
$$

tzn.

\section{Przyklad 2.}

$$
w_{A}=7 \% \quad w_{B}=93 \%
$$

Podać skład portfela z linii rynku kapitałowego obarczonego ryzykiem 3\% w odniesieniu do akcji i obligacji z przykładu 1. Określić zysk, jaki przynosi ten portfel.

Zadanie sformułowane jest prawidłowo, bo $s=3 \in\left\langle 0 ; s_{c}\right\rangle=\langle 0 ; 7,65\rangle$.

Zysk tego portfela obliczamy $\mathrm{z}$ równania linii rynku kapitałowego jako stycznej do hiperboli bądź równania prostej przechodzącej przez punkty D i C. W tym drugim przypadku korzystając ze wzoru (5) mamy:

$$
z=2+\frac{13,46-2}{7,65} \cdot 3=6,49
$$

czyli $z=6,49 \%$.

Udział obligacji w tym portfelu rynkowym obliczamy ze wzoru (11)

$$
w_{D}=1-\frac{3}{7,65}=0,61
$$

czyli $w_{\mathbf{D}}=61 \%$

Udział akcji A w portfelu obliczamy ze wzoru (12) 


$$
w_{A}=\frac{\left|\begin{array}{cc}
6,49-0,61 \cdot 2 & 14 \\
1-0,61 & 1
\end{array}\right|}{6-14}=0,02,
$$

czyli $\mathbf{w}_{\mathrm{A}}=\mathbf{2 \%}$

Wreszcie

$$
\mathrm{w}_{\mathrm{B}}=1-\mathrm{w}_{\mathrm{A}}-\mathrm{w}_{\mathrm{D}}=1-0,61-0,02=0,37,
$$

czyli $\mathbf{w}_{B}=\mathbf{3 7} \%$.

\section{Przyklad 3.}

W powyższych przykładach występujące tam obligacje przynosiły zysk $2 \%$. Po pewnym czasie zysk z tych obligacji znacznie wzrósł, co spowodowało wzrost ich ceny. Za pieniądze uzyskane $\mathrm{z}$ ich sprzedaży zakupiono akcje $\mathrm{A}$ i B. Podać skład portfela $\mathrm{z}$ linii rynku kapitałowego przynoszącego zysk w wysokości $20 \%$ oraz określić ryzyko, jakim jest obarczony ten portfel.

Ze wzoru (5) mamy

$$
20=2+\frac{13,46-2}{7,65} \cdot s,
$$

skąd

$\mathrm{s}=12,02 \%$

Ze wzoru (11) mamy

$$
w_{D}=1-\frac{s}{s_{c}}=1-\frac{12,02}{7,65}=-0,57
$$

tzn.

$\mathbf{w}_{\mathrm{D}}=-\mathbf{5 7 \%}$

$\mathrm{Z}$ kolei z (12) mamy

$$
w_{A}=\frac{\left|\begin{array}{cc}
z-w_{D} \cdot z_{D} & z_{B} \\
1-w_{D} & 1
\end{array}\right|}{z_{A}-z_{B}}=\frac{\left|\begin{array}{cc}
20+0,57 \cdot 2 & 14 \\
1+0,57 & 1
\end{array}\right|}{6-14}=0,10,
$$

tzn.

$\mathrm{w}_{\mathrm{A}}=\mathbf{1 0 \%}$

$\mathrm{Na}$ koniec

$$
\mathrm{w}_{\mathrm{B}}=1-\mathrm{w}_{\mathrm{D}}-\mathrm{w}_{\mathrm{A}}=1,47,
$$


$\mathrm{czyli}_{\mathrm{B}}=\mathbf{1 4 7 \%}$

Ilustrację graficzną stanowi rysunek 3 .

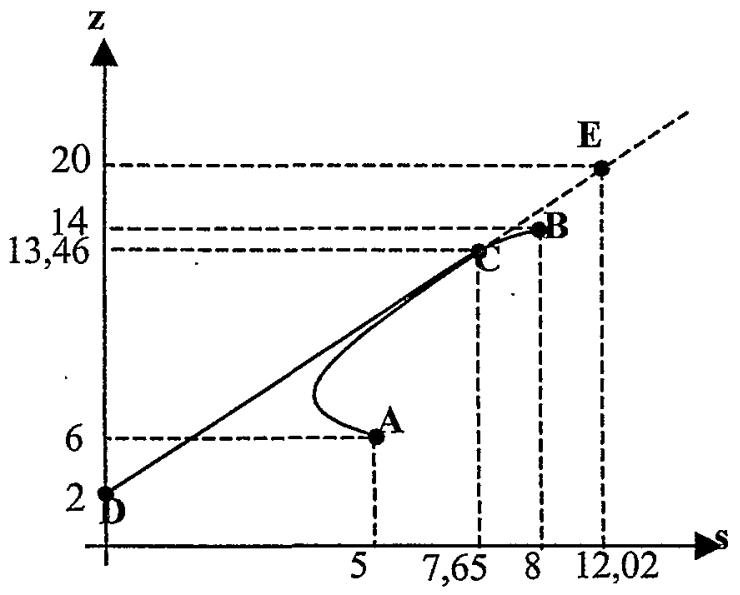

Rysunek 3

Krótka sprzedaż

$\mathrm{Na}$ powyższym rysunku półprosta DCE jest linią rynku kapitałowego. Punkt $\mathrm{C}=(7,65 ; 13,46)$ obrazuje portfel rynkowy złożony w $7 \% \mathrm{z} \mathrm{A}$ oraz w $93 \%$ z B. Na odcinku DC, w zależności od stopnia skłonności do ryzyka, znajdują się portfele złożone $\mathrm{z}$ akcji $\mathrm{A}, \mathrm{B}$ oraz obligacji $\mathrm{D}$. Punkt $\mathrm{E}=(12,02$; 20) obrazuje portfel z linii rynku kapitałowego złożony w $10 \% \mathrm{z}$ A oraz $147 \%$ z B. Udział obligacji D w tym portfelu jest ujemny i wynosi $(-57 \%)$.

\section{Uwagi końcowe}

Każdy klasyczny wykład $\mathrm{z}$ teorii portfela rozpoczyna się obszernym rozdziałem dotyczącym portfela dwuskładnikowego. Opracowania te rażą brakiem przejrzystej interpretacji geometrycznej. Portfele wieloskładnikowe wykorzystują te interpretacje, gdyż w szczególności istotne są powiązania akcji między soba.

W literaturze specjalistycznej podaje się równanie linii rynku kapitałowego, ale nie podaje się wzorów na ryzyko i zysk portfela rynkowego. Nie podaje się również wzorów na udziały $w$ portfelu odpowiadających dowolnemu punktowi z linii rynku kapitałowego. Jest to związane z pomijaniem równania hiperboli obrazującego zależność między ryzykiem a zyskiem portfela dwuskładnikowego. Współrzędne punktu $\mathrm{C}$ mają kluczowe znaczenie przy wybieraniu $\mathrm{z}$ linii rynku kapitałowego portfela $\mathrm{z}$ narzuconym $\mathrm{z}$ góry poziomem ryzy- 
ka bądź zysku. Niniejsza praca wypełnia tę lukę. W pracy zilustrowano też zagadnienie krótkiej sprzedaży.

Pojęcie portfela rynkowego rozważa się wyłącznie w odniesieniu do portfela złożonego $\mathrm{z}$ dwóch rodzajów akcji i jednego rodzaju obligacji. Kłopoty $\mathrm{z}$ przeniesieniem podanej wyżej teorii na przypadek portfeli wieloskładnikowych polegają na tym, że począwszy od portfela trójskładnikowego, nie istnieje przejrzysty odpowiednik równania określającego związek pomiędzy zyskiem a ryzykiem. W zależności tej dla portfela dwuskładnikowego występują stopy zwrotu, odchylenia standardowe i współczynnik korelacji dwóch akcji. W portfelach wieloskładnikowych występują ponadto udziały wybranych akcji (w trójskładnikowym - jeden udział, w czteroskładnikowym - dwa udziały, itd.). W portfelu rynkowym zasadnicze znaczenie ma odpowiednia styczna do hiperboli, jej równanie i punkt styczności z hiperbola. Oznacza to niemożliwość przeniesienia tego zagadnienia na przypadek portfela złożonego $\mathrm{z}$ wielu rodzajów akcji (co najmniej trzech) i jednego rodzaju obligacji.

Autor niniejszej pracy, poprzez modyfikację pojęcia portfela rynkowego, polegającą na wprowadzeniu nowego pojęcia tzw. portfela o ryzyku dowolnie małym, uzyskał możliwość jednolitej charakteryzacji dla portfeli o dowolnej ilości składników. Odpowiednia praca przygotowywana jest do druku.

\section{Literatura}

[1] CHIANG A. C., 1994, „Podstawy ekonomii matematycznej”, PWE, Warszawa

[2] ELTON E. J., GRUBER M. J., 1991, „Modern portfolio theory and investment analysis", Wiley, New York

[3] JAJUGA K., JAJUGA T., 1999, „Inwestycje”, PWN, Warszawa

[4] MARKOWITZ H. M., 1959, „Portfolio selection - efficient diversification of investments", Yale University Press, New Haven.

[5] KOLUPA M., PLEBANIAK J., 2000, „Budowa portfela lokat”, PWE, Warszawa

[6] KOSZELA G., 2001, „Analiza geometryczna zależności między ryzykiem a zyskiem w dwuskładnikowym portfelu akcji", Metody ilościowe w badaniach ekonomicznych - II, red. naukowa: B. Borkowski, A. Orłowski, SGGW, Warszawa, str. 119-129.

[7] KOSZELA G., 2003, „Analiza portfela dwuskładnikowego”, Roczniki Nauk Rolniczych, Seria G, T. 90, Z. 2, Wydawnictwo Naukowe PWN, Warszawa, str.113-127.

[8] ELLIOTT R., KOPP E., 1999, „Mathematics of financial markets”, Springer Verlag, New York

[9] HULL J. C., 2000, „Options futures and other derivatives”, Englewood Cliffs, Practise-Hall

[10] KARATZAS I., 1998, „Methods of mathematical finance”, Springer Verlag, New York 
[11] SCHÄL M., 2000, „Portfolio optimalization and martingale measures”, Mathematical Finance, vol. 10, Blackwell Publishers Ltd, Boston.

\section{The Analysis of Market Portfolio}

\section{Abstract}

Specialist bibliography offers an equation of the CML, but no formulae for market portfolio's risk and return. It is connected with the omission of the equation of hyperbola, illustrating the interdependence between risk and return of a two-element portfolio. Co-ordinates of point $\mathrm{C}$ are the key for the selection of a portfolio with a predetermined risk of return from a CML. This paper fills in this gap. The paper also illustrates an issue of the short sale.

Problems with the application of the above theory to multi-element portfolios consist in the fact that, starting from three-element portfolio, three is no clear equivalent of the equation determining the relation between return and risk. In a market portfolio the fundamental importance is attached to an adequate tangent to the hyperbola, its equation, and a point of tangency with the hyperbola. It means that it is impossible to apply the problem to the case of a portfolio assembled of a range of stocks (at least three) and one kind of bonds.

Modifying the notion of a market portfolio by introducing a new notion of the so-called arbitrarily small risk portfolio, the author of this paper has achieved the possibility of a uniform characterization of portfolios assembled from any number of elements. A paper on the subject is prepared for publication. 